
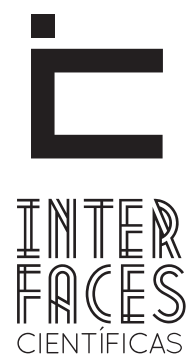

HUMANAS E SOCIAIS

\title{
MINERANDO CIÊNCIA E TECNOLOGIA NO MAR DAS CANÇ̃̃ES DE GILBERTO GIL
}

Claudia Sisan Silva de Santana ${ }^{1}$ Marcelo Cunha ${ }^{3}$

Trazíbulo Henrique Pardo Casas $^{5}$

\author{
Patricia Nicolau Magris ${ }^{2}$ \\ Marcos Grilo Rosa ${ }^{4}$ \\ Hernane Borges de Barros Pereira ${ }^{5}$
}

\section{RESUMO}

Este é um estudo sobre as canções que discorrem sobre ciência/tecnologia na obra do compositor Gilberto Gil e as redes semânticas. Este cidadão, de olhos perscrutadores, direcionou um olhar sobre ciência e tecnologia e, por meio de metáforas e outras imagens, fez convergir arte e ciência no mesmo fio criativo. A carreira do compositor foi dividida em três fases, a fase aqui recortada será a primeira que denominamos de Fase Intuitiva. Utilizando a Mineração de dados, apresentamos doze canções dessa fase, as quais foram tratadas, representadas e analisadas por
Redes Semânticas. 0 maior componente tem $82 \%$ dos vértices. A análise desse componente indica-nos a importância de vários conceitos sobre Criação do Conhecimento de Ciência e Tecnologia. A topologia sugere que a rede da primeira fase é uma Rede mundo pequeno e livre de escala.

\section{PALAVRAS-CHAVE}

Redes Semânticas. Difusão do Conhecimento Técnico-científico. Canção 


\section{ABSTRACT}

This is a study of the songs on science and technology within the composer Gilberto Gil work and their semantic networks. This citizen of searching eyes focused a look over science and technology and, through metaphors and other images, he has brought together art and science in the same creative wire. The composer's career was divided into three phases. In this article, we will address the first phase we call Intuitive Phase. Using Data Mining as a starting point, we present twelve songs of this phase, which were treated, represented and analyzed by semantic network.

\section{RESUMEN}

En este artículo analizamos las canciones que hablan de ciencia y tecnología en la obra del cantautor Gilberto Gil con el soporte de redes semánticas. Este ciudadano de ojos investigadores, dirigió una mirada a la ciencia y la tecnología y, a través de metáforas y otras imágenes, ha convergido el arte y la ciencia en el mismo hilo creativo. Su carrera la hemos dividido en tres fases. Aquí presentaremos la primera fase a que llamamos Fase Intuitiva. Hemos realizado la minería de datos de doce canciones de esta fase, que fueron tratadas, representadas y analizadas a partir de redes semánticas. El componente más grande que tiene el
The largest component has $82 \%$ of the vertices. The analysis of this component shows us the importance of several concepts about creation of knowledge on science and technology. The topology of the semantic network associated to this phase suggests that the network is both a small world and scale-free network.

\section{KEYWORDS}

Semantic Networks. Diffusion of Technical and Scientific Knowledge. Song

$82 \%$ de los vértices. El análisis de este componente nos indica la importancia de diversos conceptos con respecto a la creación del conocimiento sobre ciencia y tecnología. La topología sugiere que la red semántica de la primera fase presenta el fenómeno mundo pequeño además de una distribución libre de escala.

\section{PALABRAS CLAVE}

redes semánticas. Difusión del conocimiento técnico-científico. Canción. 


\section{INTRODUÇ̃̃̃o}

O universo das canções é repleto de características e representações da cultura de um povo, de uma cidade de um país. A necessidade de cantar a própria realidade ou suas subjetividades sempre esteve implícita em um modo de ser e de estar no mundo. Concepções que permeiam as mentes dos compositores e a verve que os alimenta estão grafadas em um imaginário repleto de singularidades e emoções, que é o mundo das canções. Deforma que o nosso cotidiano é repleto de canções, por isso a ideia de refletir sobre a importância da Canção como difusora de diversos tipos de conhecimentos.

Este artigo é uma síntese da fase inicial da pesquisa sobre Canções do compositor Gilberto Gil, que tem nas suas letras, temas que tratam de ciência e tecnologia. É possível mapear dentro da extensa obra do compositor, que em 2014 completou 72 anos de idade e uma carreira girando em torno de 50 anos, um conjunto relevante de canções que trazem no seu bojo conteúdos recorrentes sobre ciência e tecnologia.

Para melhor compreensão do objeto estudado, a obra do artista foi dividida em três fases e classificada cronologicamente durante a carreira do compositor, cantor, artista, político profissional: Telúrica (intuitiva) que vai de 1967 até 1980; Parabolicamará (transição) que vai de 1981 até 1996 e a Quântica (propositiva) que vai de 1997 até os dias atuais.

Dentre as três fases citadas acima, a base que servirá para a mineração e construção das redes semânticas neste artigo, será a Telúrica (intuitiva) que vai de 1967 até 1980. As canções foram selecionadas considerando elementos explícitos, relacionados com ciência e tecnologia.

Fase onde o compositor ainda é muito jovem e percebem-se nesse período, pensamentos paradoxais. Em um momento, Gilberto Gil convictamente anuncia a importância da nova tecnologia e no momento se- guinte a refuta. Essa dualidade pode ser mais claramente percebida nas canções: Cérebro Eletrônico, e Lunik9. Em um trecho de Cérebro Eletrônico ilustra: "O cérebro eletrônico faz tudo, faz quase tudo, mas ele é mudo".

Já em Lunik9, ele faz uma convocação aos poetas e seresteiros para que todos cantassem o luar, antes que perecessem diante da ida do homem a lua. A incerteza, também, permeava o imaginário do compositor nessa fase. Vejamos uma declaração do próprio Gilberto Gil sobre a Canção Lunik9: “Recebi o impacto da notícia do pouso (suave, segundo as avaliações) do Lunik9 na lua com orgulho e ponderação: estávamos conquistando o espaço, mas aonde isso ia dar? [...]" (GILBERTO GIL apud RENNÓ, 2014, p. 70). Esse era um momento de muita especulação sobre a chegada do homem à lua e a descobertas de outros planetas. Em outro trecho confirma a preocupação:

\footnotetext{
Lunikg apresentava um contraponto conservador, uma atitude ecológico-reativa, um temor exagerado da tecnologia e de que se inaugurava a possibilidade de extinção do próprio luar [...] a inspiração nasceu de uma profunda assunção de um sentido trágico de meu tempo.
}

Dentro desse contexto, este estudo pretende apresentar reflexões sobre o processo de Difusão do Conhecimento (DC) sobre Ciência e Tecnologia com o auxílio da Música brasileira. As palavras relacionadas com esta temática, foram retiradas e tratadas com 0 apoio da Teoria de Redes, mais especificamente trabalha-se com Redes Semânticas, um dos sistemas de representação do conhecimento.

0 ponto de partida deste artigo consiste nas seguintes proposições: por um lado, a canção como importante veículo de difusão do conhecimento, principalmente para o público não especializado, e, por outro lado discutir as redes semânticas como uma nova ferramenta de análise de conteúdo e mineração de dados. 
Este trabalho está dividido em quatro partes. $\mathrm{Na}$ primeira faz-se a imbricação de Gilberto Gil e seu percurso como artista e político. A segunda parte problematiza o universo de canções escolhidas e os eventos científicos pertinentes da época. A terceira seção apresenta as redes semânticas. E por último as primeiras interpretações e conclusões, revelando a análise qualitativa realizada.

\section{COMPOSITOR, MÚSICO, POETA E O POLÍTICO PROFISSIONAL}

Tratar sobre Gilberto Gil é discorrer sobre uma pessoa provocadora, um agitador cultural por natureza. Alguém que tem dialogado com o "contemporâneo" constantemente, estando sempre à frente do seu tempo. No Festival da Canção de 1968, ainda jovem, Gil defendeu uma canção de nome Domingo no Parque, onde misturou a tradição mítica (berimbaus) com as guitarras dos Mutantes (influência dos Beatles), sob a regência da orquestrado maestro Rogério Duprat.

A mistura de tais elementos foi considerada inovadora, mas também "transgressora" e "ousada" por alguns segmentos da sociedade civil. Ele desencadeou reações e debates sobre a influência da cultura norte-americana no País. Gil "reinventa a tradição", (como nos ilustra Hobsbawm e Ranger (1984). O historiador constrói o passado a partir do presente: "pensando e expressando opiniões a respeito do presente e suas questões e falando a respeito delas." Concebe a possibilidade de diferentes interpretações históricas sobre o mesmo evento.

Acepção proposta por Hobsbawn (1984, p. 75) esclarece que:

[...] muitas vezes tradições que parecem ou são consideradas antigas são bastante recentes, quando não inventadas. [...] elas podem ser inventadas, construídas e formalmente institucionalizadas. Podem surgir de maneira em período limitado e determinado de tempo e se estabelecer com enorme rapidez.
Provoca ainda, quando cria junto com Caetano Veloso, Tom Zé e outros artistas o movimento tropicalista. Inaugurando uma era, em que, criticava o conservadorismo de direita, imprimindo em suas letras conteúdos que se aproximavam dos costumes da cena cotidiana. A tropicália definitivamente mudava o panorama da cultura brasileira.

Gil se destacou ainda, quando foi preso, e depois exilado. Foi considerado persona non grata pela Ditadura militar no Brasil e no retorno do seu exílio, cria em 1976 o Show “Os mais Doces Bárbaros”.

Pode-se afirmar ainda, que, o provocador Gil é detentor de uma "multiplicidade identitária", na verdade aquele "sujeito pós-moderno" na perspectiva de Hall (2002). Diferencia-se pelas múltiplas faces: o artista, o poeta, o político. Como político profissional se filia ao Partido Verde, onde elege-se vereador em 1989 pela comarca de Salvador/BA, com quase 12 mil votos. A militância da época tinha como pauta a sustentabilidade. Salientando que o debate sobre ecologia ganhou força desde a década de 1970. Passeatas e Manifestações deram início a uma verdadeira guerra a favor da ecologia, principalmente contra a guerra nuclear.

Em 2003, foi ministro do Governo Lula. A sua atuação no Ministério da Cultura foi exitosa, durante cinco anos, devido a captação de verbas importantes para a pasta da Cultura. Pode-se afirmar ainda, que, o conceito de Diversidade cultural e o Fomento das Produções Periféricas foi o tom adotado por ele, enquanto Política Cultural.

Ainda sobre sua passagem no Ministério da Cultura, evidencia-se a discussão sobre direitos da propriedade intelectual e cultura digital. A matéria da New York Times de onze de marco de 2007, intitulada Gilberto Gil Hearsthe Future, Some Rights Reserved (Gil ouve o futuro, com alguns direitos reservados), faz referência ao acordo com a Creative Commons em 2003. Elogia a atuação do Ministro, evidenciando que: "raramente no mundo da políticae das artes encon- 
tra-se uma personalidade com tantas convergências como o Sr. Gil [...]", Diz ainda "Sr. Gil surgiu como um ator central na busca global por formas mais flexíveis dedistribuição de obras artísticas" (ROHTER, LARRY, New York Times, 2014).

Promovendo a inclusão digital e fomentando um discurso sobre autoria, a performance do artista/político acaba promovendo o que Homi Bhabha (2005) chamou de "fissura" das estruturas.

\section{CANTAR CIÊNCIA}

Este estudo discute ciência e arte, partindo da premissa que a canção é um instrumento importante no processo de difusão cientifica. Para Ulhôa (1999), a canção é formada pela relação entre letra e música, dividida em partes, sãso constituídas por versos que são organizados em estrofes. Segundo o dicionário Aurélio (2014), a palavra canção, substantivo feminino singular, vem do latim cantione, canto, canção; encanto, encantamento.

E por causa desse encantamento, podemos afirmar que, a canção é uma transportadora de ideias e de sensações, recheadas de temas que atravessam cotidianamente nossas vidas. Conjecturas são suscitadas por meio delas, inferindo e ou interferindo na nossa sociabilidade.

A relação entre música e ciência está presente neste extrato da obra do compositor Gilberto Gil, o mapeamento foi realizado de 1963 até 1980 . Com o propósito de entender o significado desses aportes científicos em formato canção é que separamos doze delas.

O extrato recortado para análise é o da primeira fase, aqui denominada de Telúrica (intuitiva). A década de 1960 foi marcada, principalmente, por avanços na área aero espacial, na comunicação e internet. Aquele momento político foi “delicado" em virtude da guerra fria (bloco capitalista $x$ comunista). A consolidação da televisão e o período da ditadura militar completavam o cenário das décadas de 1960 e 1970.

Nesse contexto, as canções que apresentam elementos de ciência e tecnologia foram tratadas de modo a extrair conhecimento, usando uma técnica de mineração de dados e análise de redes semânticas. A seguir, apresentamos na Tabela 1 uma breve caracterização da seleção de 12 canções aqui propostas da fase Telúrica/intuitiva. 
Tabela 1 - Caracterização dos álbuns de Gilberto Gil da fase Telúrica (intuitiva) em relação aos principais eventos técnico-científicos

\begin{tabular}{|c|c|c|c|}
\hline CANÇÃO & ÁLBUM & $\begin{array}{l}\text { DATA } \\
\text { (ANO) }\end{array}$ & $\begin{array}{c}\text { PRINCIPAIS EVENTOS CIENTÍFICOS } \\
\text { Décadas de } 1960 \text { e } 1970\end{array}$ \\
\hline Lunik 9 & Louvação & 1967 & $\begin{array}{l}\text {-Os EUA lançam o primeiro satélite meteorológico. } \\
\text {-Pílula anticoncepcional é lançada no mercado. } \\
\text {-A IBM lança o primeiro computador electrónico IBM: o RAMAC } \\
305.1963 . \\
\text { - Sonda espacial soviética Luna IV pousa na Lua. } \\
\text {-16 de Junho - Russa Valentina Tereshkova torna-se a primeira mu- } \\
\text { lher a ir ao espaç01964. } \\
\text {-IBM lança o circuito integrado, ou chip1965. } \\
\text {-16 de Fevereiro - A sonda espacial Venera, desenvolvida pelo pro- } \\
\text { grama espacial soviético, chega ao planeta Vênus. } \\
\text { - Primeiras máquinas criadas pelo homem a entrar na atmosfera de } \\
\text { outro planeta.Foi a primeira a fotografar e enviar à Terra ima- } \\
\text { gens de outro planeta.1967. } \\
\text {-27 de Janeiro - Incêndio da nave Apollo } 1 \text { mata os astronautas } \\
\text { americanos Virgil Grissom, Edward White e Roger Chaffee. }\end{array}$ \\
\hline $\begin{array}{l}\text { A luta contra a lata } \\
\text { ou a falência do } \\
\text { café }\end{array}$ & $\begin{array}{l}1968-G i l- \\
\text { berto Gil }\end{array}$ & 1968 & $\begin{array}{l}\text {-3 de Dezembro - o cirurgião sul-africano ChristiaanBarnard fazia } \\
\text { o primeiro transplante de coração humano. O paciente só sobre- } \\
\text { viveu } 18 \text { dias, morrendo de infecção pulmonar. } \\
\text {-Um mês depois da operação espectacular, Barnard fez o segundo } \\
\text { transplante de coração e, desta vez, com grande sucesso: o den- } \\
\text { tista Philip Blaiberg viveu um ano e sete meses com o coração } \\
\text { novo.1968. } \\
\text { - Objeto semi-identificado }\end{array}$ \\
\hline 1968-Gilberto Gil & 1968 & & $\begin{array}{l}\text {-23 de Abril - Em Paris, França, é feito o primeiro transplante do } \\
\text { coração na Europa. } \\
\text {-26 de Maio - O médico Euryclides de Jesus Zerbini realiza, em João } \\
\text { Boiadeiro, o primeiro transplante de coração do Brasil. }\end{array}$ \\
\hline Cérebro Eletrõnico & $\begin{array}{l}1969-G i l- \\
\text { berto Gil }\end{array}$ & 1969 & $\begin{array}{l}\text {-13 de julho: A União Soviética lança a sonda lunar lua } 15 . \\
\text {-No Laboratórios Bell (EUA), Willard S. Boyle e George Smithin- } \\
\text { ventaram o CCD. Tecnologia da camêra digital. }\end{array}$ \\
\hline Futurível & $\begin{array}{l}1969-G i l- \\
\text { berto Gil }\end{array}$ & 1969 & $\begin{array}{l}\text {-11 de Outubro - Lançada a Apollo } 7 \text {, cuja missão foi a primeira } \\
\text { televisionada. } \\
\text {-21 de Dezembro - Lançamento da Apollo } 8 \text { que foi a primeira nave } \\
\text { tripulada em órbita lunar.1969. }\end{array}$ \\
\hline
\end{tabular}




\begin{tabular}{|c|c|c|c|}
\hline CANÇÃO & ÁLBUM & $\begin{array}{l}\text { DATA } \\
\text { (ANO) }\end{array}$ & $\begin{array}{l}\text { PRINCIPAIS EVENTOS CIENTÍFICOS } \\
\text { Décadas de } 1960 \text { e } 1970\end{array}$ \\
\hline Vitrines & $\begin{array}{l}\text { 1969-Gil- } \\
\text { berto Gil }\end{array}$ & 1969 & $\begin{array}{l}\text {-É criado o avião Boeing } 747 . \\
\text {-É criado o avião Concorde. } \\
\text { - } 9 \text { de Fevereiro - O Boeing } 747 \text { efetua o seu primeiro voo comercial. } \\
\text { - } 2 \text { de Março - Primeiro voo de teste do Concorde. } \\
\text { - } 7 \text { de Abril - Criada a ArpaNET, embrião da Internet. } \\
\text {-20 de Julho - Neil Alden Armstrong foi o primeiro homem a pisar } \\
\text { na Lua, como comandante da missão Apollo } 11 . \\
\text {-26 de Outubro - Enviada a primeira mensagem de e-mail entre } \\
\text { computadores distantes. }\end{array}$ \\
\hline Marginália 2 & $\begin{array}{l}\text { Expresso } \\
2222\end{array}$ & 1972 & $\begin{array}{l}\text {-15 de novembro de } 1971 \text { - A Intel lança o primeiro microprocessa- } \\
\text { dor do mundo, o Intel } 4004 \text {. } \\
\text {-Em janeiro de } 1972 \text { é lançado o Odyssey 100, primeiro video ga- } \\
\text { medo mundo. }\end{array}$ \\
\hline Expresso 2222 & $\begin{array}{l}\text { Expresso } \\
2222\end{array}$ & 1972 & $\begin{array}{l}\text {-9 de fevereiro-Projeto Apollo:Apollo 14retorna à Terra depois do } \\
\text { terceiro pouso humano na Lua. } \\
\text {-28 de maio-Marte: A sonda Marte 3é lançada pela União Soviética. } \\
\text { - } 30 \text { de maio-Marte: A sondaMariner9é lançada pelosEstados } \\
\text { Unidos. } \\
\text { - } 6 \text { de junho-Programa Soyuz: é lançado o Soyuz } 11 \text {. } \\
\text { - } 30 \text { de junho- A tripulação da Soyuz } 11 \text { morre devido a uma fuga de } \\
\text { ar através de uma válvula defeituosa. } \\
\text {-2 de outubro- O engenheiro eletrônico Ray Tomlinsonenvia o pri- } \\
\text { meiro e-mail. } \\
\text { - } 3 \text { de novembro - OUNIX Programmer’s Manualé publicado. } \\
\text {-13 de novembro-Programa Mariner: Mariner9entra na órbita de } \\
\text { Marte. }\end{array}$ \\
\hline $\begin{array}{l}\text { Vamos passear no } \\
\text { astral }\end{array}$ & $\begin{array}{l}\text { Expresso } \\
2222\end{array}$ & 1972 & $\begin{array}{l}\text { - } 7 \text { de dezembro- lançada a Apollo 17, última nave a levar homens } \\
\text { à Lua. } \\
\text {-É fundado o Observatório Abrahão de Moraes no município de Va- } \\
\text { linhos (São Paulo, Brasil). }\end{array}$ \\
\hline $\begin{array}{l}\text { Está na cara, está } \\
\text { na cura }\end{array}$ & $\begin{array}{l}\text { Expresso } \\
2222\end{array}$ & 1972 & $\begin{array}{l}\text { - O TMO- Transplante de medula óssea, surgiu na década de } \\
\text { 70, graças ao pioneirismo de E. Donnall Thomase colabora- } \\
\text { dores, reconhecido mais tarde com o Prêmio Nobelem Fisio- } \\
\text { logia e Medicina. } \\
\text { - Os paleontólogos norte-americanos Niles Eldredgee Stephen } \\
\text { Jay Gould criaram a teoria evolutiva denominada Equilíbrio } \\
\text { pontuado1. }\end{array}$ \\
\hline
\end{tabular}




\begin{tabular}{|c|c|c|c|}
\hline CANÇÃO & ÁLBUM & $\begin{array}{l}\text { DATA } \\
\text { (ANO) }\end{array}$ & $\begin{array}{l}\text { PRINCIPAIS EVENTOS CIENTÍFICOS } \\
\text { Décadas de } 1960 \text { e } 1970\end{array}$ \\
\hline Cibernética & $\begin{array}{l}\text { Gilberto Gil } \\
\text { ao vivo }\end{array}$ & 1974 & $\begin{array}{l}\text { - } 3 \text { de Abril de 1973-Martin Cooper realiza a primeira chamada a } \\
\text { partir de um Telefone Celular. } \\
\text {-14 de maio } 1973 \text { - Lançamento do laboratório espacial Skylab. } \\
\text { - Dezembro de } 73 \text { - A sonda espacial Pioneer 10passa por Júpiter. } \\
\text {-1973 Robert Metcalfe começa a criar a Ethernet. } \\
\text { - } 11 \text { de setembro de } 1973 \text { - golpe militar no Chile, liderado pelo ge- } \\
\text { neral Augusto Pinochet, derruba o governo de Salvador Allende. } \\
\text { - Com derrota dos Estados Unidos, termina a Guerra do Vietnã. } \\
\text { - } 5 \text { de março de } 1974 \text { - O general Ernesto Geisel assume a presidên- } \\
\text { cia do Brasil. } \\
\text { - } 9 \text { de agosto de } 1974 \text { - Após o caso Watergate, Richard Nixon re- } \\
\text { nuncia à presidência dos EUA. }\end{array}$ \\
\hline $\begin{array}{l}\text { Essa é para tocar } \\
\text { no Rádio }\end{array}$ & Refazenda & 1975 & $\begin{array}{l}\text {-1975 - A missão espacial Viking I explora o planeta Marte. } \\
\text {-É lançado o Altair 8800, o primeiro computador doméstico. } \\
\text {-A televisão em cores começa a se tornar popular no final dos anos } \\
1970 . \\
\text { - } 25 \text { de julho de 1978, na Inglaterra Nascia na década de } 1970 \text { o } \\
\text { primeiro bebê de proveta, Louise Brown, uma saudável menina } \\
\text { de olhos azuis. }\end{array}$ \\
\hline
\end{tabular}

Fonte: Almanaque Ediouro Anos 1970 e Anos 1980, Almanaque Abril e livro A Informação de James Gleick

\section{A MINERAÇÃO DE DADOS E AS REDES SEMÂNTICAS}

A Rede Semântica foi escolhida, porque o elemento principal que aparece relacionado em uma rede semântica é a palavra, que é, um dos elementos da canção. Esse é o elemento principal dessa análise. Consideramos a palavra elementos que traz toda a semântica que tem em si mesmo (e.g. "Cérebro eletrônico" = "cérebroeletrônico").

Rede Semântica como forma de representação adéqua-se a uma variedade de métodos computacionais e tem sido cada vez mais estudada por cientistas de diversas áreas. Uma rede semântica é, então, a rede de um conjunto de elementos - palavras, conceitos ou entidades - interconectados, que estão relacionados por meio dos signicados (i.e. símbolos linguísticos) (STERNBERG, 2011).

Atualmente, as Redes semânticas vêm sendo representadas matematicamente pela teoria dos grafos, em que cada vértice da rede representa uma palavra e as arestas representam ligações entre essas palavras. No nosso caso, as palavras são conectadas se estiverem no mesmo verso.

Abaixo um exemplo dessa conectividade com a primeira e segunda estrofes da canção Cérebro Ele- 
trônico. Como já dissemos as doze canções da fase Telúrica (intuitiva) foram tratadas e transformadas em Redes Semânticas. A rede possui 48 componentes (Figura 1a) e o maior componente tem $82 \%$ dos vértices (Figura 1b).
Ao analisarmos o componente maior, percebemos que ele representa a fase que denominamos de Telurica/intuitiva das Canções de Ciência e Tecnologia de Gilberto Gil. De acordo com os valores das propriedades da rede (Tabela 2) e considerando o método de Wattts e Strogatz (1998) e Watts(1999), caracterizamos a rede como mundo pequeno.

Figura 2 - Rede Geral da fase Telúrica (intuitiva), considerando as 12 canções selecionadas

a) Redes semântica com 48 componentes

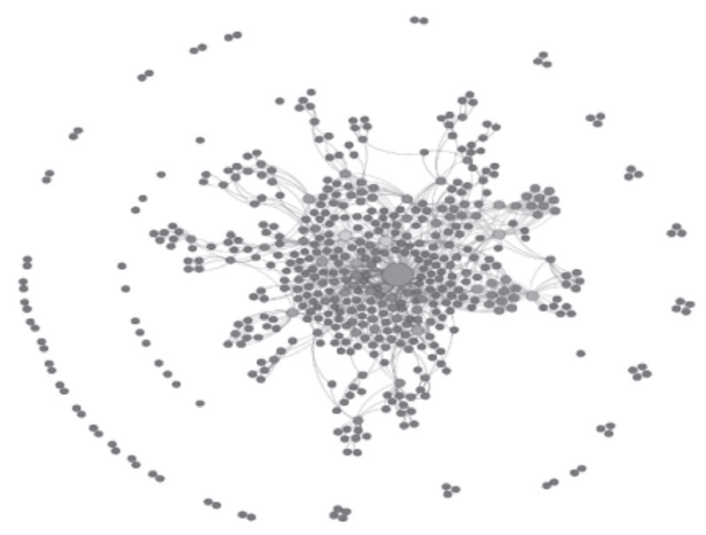

b) Componente gigante da rede semântica

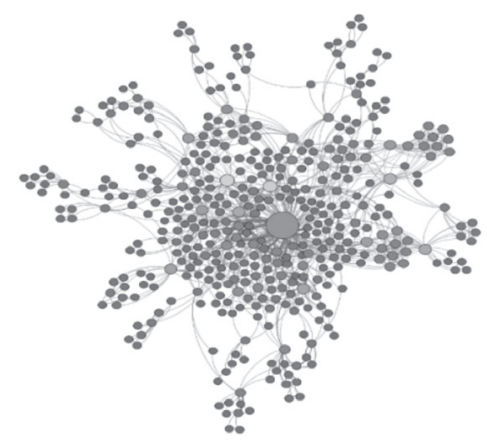

Fonte: Autores, 2015.

Fonte: Autores, 2015.

Tabela 2 - Propriedades da rede Geral Telúrica (intuitiva)

\begin{tabular}{|l|l|l|l|l|l|l|l|l|l|}
\hline Redes & $\mathrm{n}=|\mathrm{V}|$ & $\mathrm{m}=|\mathrm{E}|$ & $<\mathrm{k}>$ & $\mathrm{D}$ & Densidade & $\begin{array}{l}\text { Componentes } \\
\text { (\% de vértices) }\end{array}$ & $\mathrm{C}_{\mathrm{ws}}$ & $\mathrm{C}$ & $\mathrm{L}$ \\
\hline Geral & 516 & 1233 & 4,78 & 8 & 0,009 & $48(100 \%)$ & 0,66 & 0,81 & 3,53 \\
\hline $\begin{array}{l}\text { Componente } \\
\text { gigante }\end{array}$ & 426 & 1176 & 5,52 & 8 & 0,013 & $1(82,56 \%)$ & 0,74 & 0,8 & 3,53 \\
\hline
\end{tabular}

Fonte: Autores, 2015. 
Na plotagem da rede egocêntrica (Figura 2) colocamos a palavra com maior grau no centro. Esta palavra é a palavra SER. Considerando a inspeção visual, é possível conjecturar que a palavra SER (Importante salientar que temos consciência, que SER é um dos verbos de ligação mais importantes da língua portuguesa), é representada nas canções de Gilberto Gil, como veículo propulsor da sua construção semântica, ou seja, implica o sujeito como construtor de conhecimento, e sendo assim, projeta, os atributos de Ciência e Tecnologia como sendo elementos que emergem do "SER" (homo faber e homo techné). E é o próprio Gil, que nos oferece postulados históricos para essa compreensão aqui explicitada nas Redes Semânticas e apresentadas neste trabalho:

O fato de eu ter sido violentado na base de minha condição existencial - meu corpo - e me ver privado da liberdade da ação e do movimento, do domínio pleno de espaço-tempo, de vontade e de arbítrio, talvez tenha me levado a sonhar com substitutivos e a, inconscientemente, pensar nas extensões mentais e físicas do homem, as suas criações mecânicas; nos comandos tele-acionáveis que aumentam sua mobilidade e capacidade de agir e criar. (GILBERTO GIL apud RENNÓ,2003, p. 113)

Sobre essa construção, ele pontua ainda:

Eu estava preso havia umas três semanas, quando o sargento Juarez me perguntou se eu não queria um violão. Eu disse: 'Quero'. E ele me trouxe um, com a permissão do comandante do quartel. O violão ficou comigo uns quinze dias. Aí, eu, que até então não tinha tido estímulo para compor (faltava a 'voz' da música, o instrumento), fiz Cérebro Eletrônico, Vitrines e Futurível - além de uma outra, também sob esse enfoque, ou delírio, científico-esotérico, que possivelmente ficou apenas no esboço e eu esqueci. (GILBERTO GIL apud RENNÓ,2003, p. 113)

Podemos verificar que o violão, também, aparece como uma necessidade extensionista do "Ser" humano na perspectiva da vida do compositor e essa condição é intimamente relacionadas em suas canções

A condição humana é identificada como o elo do SER com a sua extensão maquínica, sugerindo a cons- trução de conhecimentos. Assim sendo, as canções de Gil, destacam um cenário frutífero dessa construção, e por outro viés analítico, elas são importantes difusoras de conhecimentos, aqui implicados e analisados na perspectiva de Ciência e Tecnologia.

Nesse sentido, a Rede representada na Figura 1b, componente gigante, demonstra o quanto o SER é o elemento negociador de sentidos para as ênfases dispostas nas canções.

Figura 2 - Rede egocêntrica com a palavra SER no centro

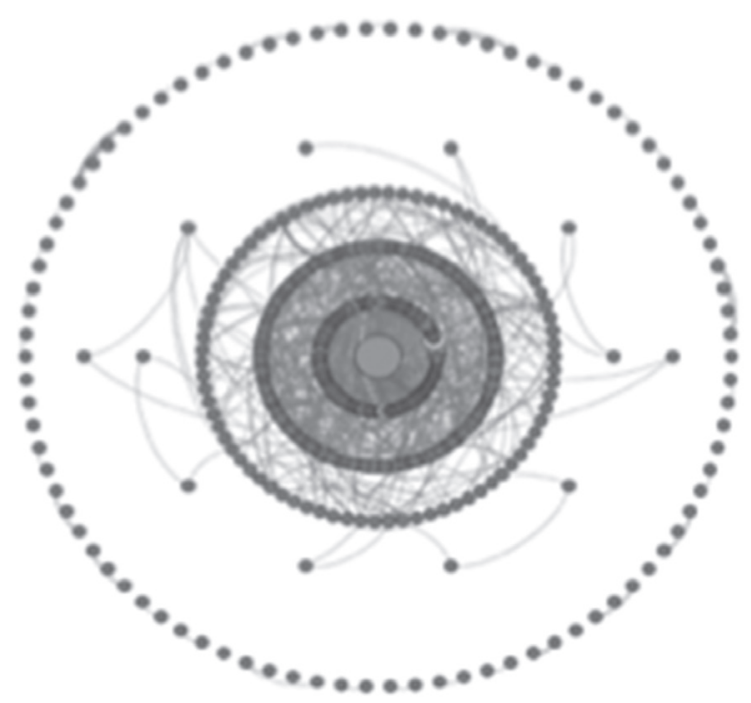

Fonte: Autores, 2015.

\section{CONSIDERAÇÕES FINAIS}

A partir da interpretação dessas primeiras redes da Fase Telúrica/intuitiva, pode-se afirmar que elas apresentam o fenômeno mundo pequeno (small world), além de serem livres de escala (scale free). 0 modelo livre de escala é capaz de descrever os inúmeros sistemas naturais e se caracteriza pela distribuição do número de conexões dos seus elementos, seguem uma lei de potência. 
As topologias das redes analisadas trazem/indicam comportamentos (e. g. eficiência) que contribuem para a difusão do conhecimento. Algumas palavras são determinantes para isso, como verificamos na Motivação de Análise destacados na parte de cima deste artigo.

O compositor traz, no tecido da música, elementos contemporâneos que compõem o espaço da sociedade da informação. Estes elementos são resignificados por meio de uma bricolagem de imagens, convidando o leitor-ouvinte não apenas observar, mas sentir por meio de efígies como a tecnologia é cantada.

Dessa forma, no decorrer do texto buscou-se abordar como a ciência, atividade humana, insere-se na Sociedade da Informação e, ainda como a música em foco, traz múltiplas imagens da ciência e tecnologia na sociedade supramencionada.

O compositor recria o cenário da sociedade da informação e aborda os elementos que a compõem tais como: bomba, nave, espaço, eletrônico, trem, rádio, cibernética, futurível, medula dentre outros. Estes aspectos reafirmam a relação do artista com as novas réguas e compassos do novo universo da tecnologia, e todos os seus riscos e desafios, mesmo de maneira intuitiva.

As canções pela sua capacidade radiofônica e comercial podem ser sim meios importantes de difusão do conhecimento. Percebe-se que há um interesse muito grande sobre ciência, na medida em que o interesse pela prática cresce continuamente, tanto entre jornalistas como entre os meios de comunicação e os governos.

Na hora em que entram na pauta do dia, assuntos como transgênicos, nanotecnologia e células-tronco embrionárias, há uma necessidade de um diálogo maior entre a ciência e a sociedade. 0 interesse é crescente e a Canção é uma grande aliada nessa jornada.

\section{REFERÊNCIAS}

ALMANAQUE ABRIL. Disponível em: <www.almanaque.abril.com.br>. Acesso em: 6 abr. 2014.

ALZER, Luiz André. Almanaque Anos 80. Rio de Janeiro: Ediouro, 2004.

BAHIANA, Ana Maria. Almanaque Anos 70. Rio de Janeiro: Ediouro, 2006.

BHABHA, Homi K. O local da cultura. Belo Horizonte: EdUFMG, 2005.

CUNHA, Marcelo do Vale. Redes semânticas baseadas em títulos de artigos científicos. 2013. Dissertação (Mestrado). Programa de Pós-graduação em Modelagem Computacional e Tecnologia Industrial SENAI-CIMATEC, 2013.

DICIONÀRIO AURÈLIO ONLINE. Disponível em: <http://www.dicionariodoaurelio.com/>. Acesso em: 15 maio 2014.

ERDOS, P. On cliques in graphs. Israel Journal of Mathematics, v.4, 1966. p.233-234.

FADIGAS, I.; PEREIRA, H. A network approach based on cliques. Physica A: Statistical Mechanics and its Applications, v.392, n.10, 2013. p.2576-2587.

GIDDENS, Anthony. As Conseqüências da Modernidade. São Paulo: Unesp, 1991.

GIL, Gilberto. Modernidade e Identidade. Rio de Janeiro: Jorge Zahar, 2002.

GIL, Gilberto. Expresso 2222. Org. Antônio Risério. Salvador: Corrupio, S/d.

GIL, Gilberto. Todas as letras. Org. Carlos Rennó. São Paulo: Cia das Letras. 2003. 
GILBERTO GIL. Disponível em: <http://www.gilbertogil.com.br/>. Acesso em: 20 maio 2014.

GIL, Gilberto e RISÉRIO, Antônio. 0 poético e o político. Rio de Janeiro: Paz e Terra S/A, 1988.

GLEICK, James. A Informação - uma história, uma teoria, uma enxurrada. São Paulo: Companhia das Letras, 2013.

HALL, Stuart. Identidade Cultural na Pós Modernidade. Trad. Tomás Tadeu da Silva \& Guacira Lopes Louro. 7.ed. Rio de Janeiro: DP\&A, 2002.

HOBSBAWM. Eric; RANGER, Terence. Invenções das Tradições. São Paulo: Paz e Terra, 1984.

OLIVEIRA, Carlos Antonio Barros de. Doces e bárbaros - um estudo sobre construções de identidades baianas. 2005. Dissertação (Mestrado em Ciências Sociais) - Programa de Pós-graduação em Ciências Sociais da Universidade federal da Bahia. Salvador, 18 de março de 2005. Disponível em <http://www.ppgcs.ufba.br/site/db/trabalhos/CarlosBarros.pdf.> Acesso em: 20 maio 2014.

RENNÓ, Carlos.(Org.). Gilberto Gil -Todas as Letras. Edição Revista e ampliada.São Paulo: Editora Companhia das Letras.2003.
REVISTA SCIENSE. Disponível em: <http://ahduvido. com.br/as-10-maiores-descobertas-cientificas-da-decada-segundo-a-science>. Acesso em: 5 abr. 2014.

ROHTER, Larry. Gilberto Gil Hears the Future, Some Rights Reserved. New York Times Journal. Published March 11, 2007. Disponível em: <http:// www.nytimes.com/2007/03/11/arts/music/11roht. html?pagewanted=all\&_r=0>. Acesso em: 5 abr. 2014.

Sternberg, R. Psicologia cognitiva. Porto Alegre, Rio de Janeiro: Artes Médicas Sul, 2011.

TATIT, Luiz. O Século da canção. São Paulo: Ateliê, 2004; Jorge Zahar, 2003.

TATIT, Luiz. A Canção, eficácia e encanto. São Paulo: Atual, 1986.

ULHÔA, M.T. Métrica derramada: prosódia musical na canção brasileira popular. Rio de Janeiro: Brasiliana, 1999.

WATTS, D. J.; STROGATZ, S. H. Collective dynamics of'small-world'networks. Nature, v.393, n.6684, 1998. p.409-410. 
1.Professora da Universidade do Estado da Bahia, Doutoranda do Programa interdisciplinar em Difusão do Conhecimento (DMMDC). Mestrado em Educação em pesquisa - Université Du Quebéc a Chicoutimi-Canadá, estudou Pedagogia e Composição e Regência. Possui especialização em Gestão de Instituição de Ensino Superior e em Jornalismo e novas mídias. Coordena junto com Marilda Santanna o grupo de Pesquisa Canto de Cada Canto, vinculado ao Programa Multidisciplinar de Pós-Graduação em Cultura e Sociedade da UFBA. E-mail: claudiasisan@hotmail.com

2. Graduação - Licenciatura em Pedagogia pela Universidade Federal da Bahia (1997) e Mestrado em Educação (ênfase em Educação, Comunicação, Tecnologia e Arquitetura) pela Universidade Federal da Bahia (2004). Professora assistente do Dep. de Educação da Universidade do Estado da Bahia - Campus I - Salvador/BA. E-mail: patmagris@gmail.br

3. Possui graduação em Física pela Universidade Federal da Bahia (2009). Mestre em Modelagem computacional e tecnologia industrial, Senai BA (2013). Doutorando em Modelagem computacional e tecnologia industrial, Senai BA. Atualmente, é professor efetivo do Instituto Federal de Educação, Ciência e Tecnologia da Bahia IFBA (2010 atual). E-mail: celaocunha@gmail.com

4. Possui graduação em Licenciatura Em Matemática pela Universidade Estadual de Feira de Santana (2001) e mestrado em Matemática pela Universidade Federal de Pernambuco (2004). Atualmente é Professor Assistente da Universidade Estadual de Feira de Santana e Membro de corpo editorial da Folhetim de Educação Matemática.

E-mail: grilo@uefs.br

5. Graduação em Engenharia Civil pela Universidade Estadual de Feira de Santana (1984), mestrado em Engenharia de Sistemas e Computação pela Universidade Federal do Rio de Janeiro (1991) e doutorado em Informática na Educação pela Universidade Federal do Rio Grande do Sul (2003). Atualmente é professor adjunto b da Universidade Estadual de Feira de Santana. E-mail: henrique@uefs.br 6. Doutorado em Engenharia Multimídia pela Universitat Politécnica de Catalunya em 2002. Atualmente é Professor Pleno do Departamento de Educação da Universidade do Estado da Bahia e Professor Associado do SENAI CIMATEC. É docente do Programa de Pós-graduação em Modelagem Computacional e Tecnologia Industrial e do Doutorado Multi-institucional e Multidisciplinar em Difusão do Conhecimento. 
